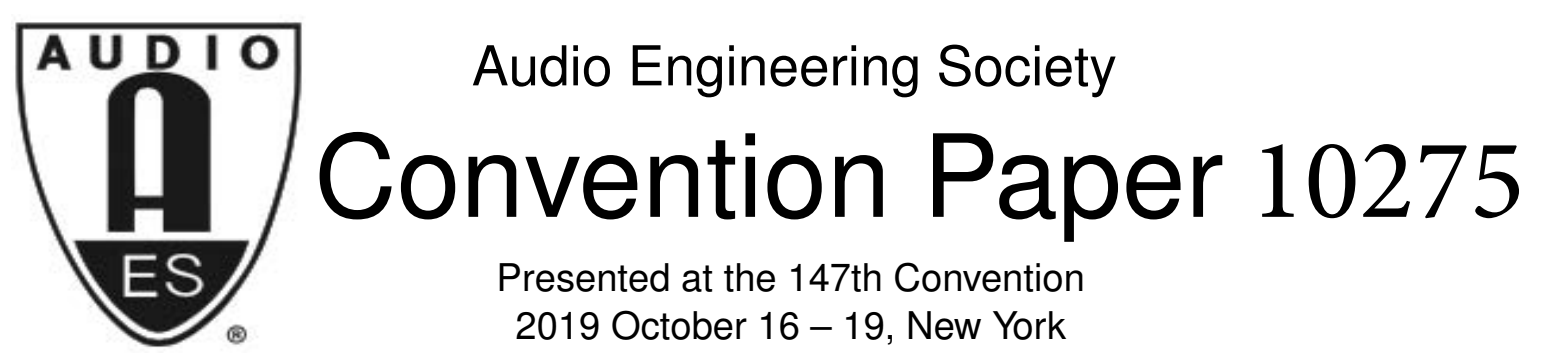

This paper was peer-reviewed as a complete manuscript for presentation at this convention. This paper is available in the AES E-Library (http://www.aes.org/e-lib) all rights reserved. Reproduction of this paper, or any portion thereof, is not permitted without direct permission from the Journal of the Audio Engineering Society.

\title{
Defining Immersion: Literature Review and Implications for Research on Immersive Audiovisual Experiences
}

\author{
Sarvesh Agrawal ${ }^{1,2}$, Adèle Simon ${ }^{1}$, Søren Bech $^{1,3}$, Klaus Bærentsen $^{4}$, and Søren Forchhammer ${ }^{2}$ \\ ${ }^{1}$ Bang \& Olufsen a/s, Bang \& Olufsen Allè 1, 7600 Struer, Denmark \\ ${ }^{2}$ Technical University of Denmark, Department of Photonics Engineering, 2800 Lyngby, Denmark \\ ${ }^{3}$ Aalborg University, Department of Electronic Systems, 9220 Aalborg, Denmark \\ ${ }^{4}$ Aarhus University, Department of Psychology, 8000 Aarhus C, Denmark \\ Correspondence should be addressed to Sarvesh Agrawal (sraj@bang-olufsen.dk)
}

\section{ABSTRACT}

The use of the term 'immersion' to describe a multitude of varying experiences in the absence of a definitional consensus has obfuscated and diluted the term. This paper presents a non-exhaustive review of previous work on immersion on the basis of which a definition of immersion is proposed: a state of deep mental involvement in which the subject may experience disassociation from the awareness of the physical world due to a shift in their attentional state. This definition is used to contrast and differentiate interchangeably used terms such as presence and envelopment from immersion. Additionally, an overview of prevailing measurement techniques, implications for research on immersive audiovisual experiences, and avenues for future work are discussed briefly.

\section{Introduction}

The field of spatial audio has grown over the last decade, leading to a plethora of words for describing new auditory experiences. Immersion is one of the terms which have gained prominence and established their dominance in the vocabulary. It is often equated to realism, naturalness, presence, and the sense of being surrounded, which has made immersion an "excessively vague, all-inclusive concept" [1]. The ambiguity in the definition of immersion for audio applications was recognized by Berg [2] who acknowledged the convoluted nature of the concept and stated that "in addition to sound, other modalities contribute to immersion and that immersion is something more complex than just a listener being surrounded by any kind of sound(s)." Nevertheless, immersion continues to be confused with terms such as envelopment [3] since the distinction between the terms and the underlying ideas are not well documented. To conduct research on immersive audiovisual experiences, there is a need to establish a clear definition of immersion.

Besides audio and acoustics, immersion has been studied in a variety of domains including video games $[4,5,6,7,8]$, virtual reality $[9,10,11,12]$, music $[13,14]$, film $[15,16,17]$, and literary works [18]. The use of immersion to describe a multitude of varying experiences and the lack of consensus on the use of terminology can lead to a mismatch between the idea to be investigated and the employed research methods [19]. Furthermore, the emergence of virtual reality and the interchangeable use with terms such as presence, involvement, and engagement creates a risk of confusion between concepts [19]. Thus, it can be chal- 
lenging to communicate and comprehend the idea to develop a better understanding of the subject. In order to communicate effectively, it is critical to formalize the meaning of immersion. The primary goal of this paper is to present an adaptable definition of immersion and highlight the implications for research on immersive audiovisual experiences. An overview of previous work on immersion is provided in Section 2, followed by a definition proposal in Section 3. Interchangeably used terms are contrasted and differentiated from immersion in Sections 4 and 5. Section 6 outlines the subjective, behavioral, and physiological measures which have been used in the literature for measuring immersion. Finally, the implications for immersive audiovisual experience research are presented in Section 7.

\section{Concept of Immersion}

Although the exact origin of immersion's conceptualization is not known, Murray [20] described the concept as:

Immersion is a metaphorical term derived from the physical experience of being submerged in water. We seek the same feeling from a psychologically immersive experience that we do from a plunge in the ocean or swimming pool: the sensation of being surrounded by a completely other reality, as different as water is from air, that takes over all of our attention, our whole perceptual apparatus ([20], p.99).

Murray expressed that immersion is not simply the outcome of the intensity of the sensory stimulation. She proclaimed that a stirring narrative can deliver immersive experiences even with a limited amount of sensory input such as in the case of books [20]. While Murray describes immersion as a psychological concept which influences an individual's attention, it has been argued that immersion is purely an objective property of the technology or the system which facilitates an experience $[21,22,23]$.

Based on a review of previous studies, there are two major perspectives on immersion: an individual's psychological state and an objective property of a technology/system. An overview of these perspectives is provided in the next sub-sections.

\subsection{Immersion as an Individual's Psychological State}

Psychological immersion, similar to Witmer and Singer's [24] idea of involvement, is understood as a user's psychological state when they are involved, absorbed, engaged, or engrossed [25]. In McMahan's [1] words, "immersion means the player is caught up in the world of the game's story (the diegetic level);" she added, "[immersion] results from the user's mental absorption in the world." McMahan de-emphasized the role of the system while focusing on the individual and the narrative. Correspondingly, Thon [26] determined that, "what is presented is more important than how it is presented [for a user to experience immersion]." This idea is exemplified by the experience of reading books where the sensory input from the stimulus is limited but the reader can construct scenarios in their mind such that they are immersed in the act of reading.

In the context of video games, Sanders and Cairns [4] established that immersion results from focusing one's attention, thoughts, and goals towards the game. The notion of 'shift of attention' is central to the concept of immersion according to Thon [26], who stated that it is the shift of attention along with the construction of mental representation in the brain which leads to an immersive experience. Brown and Cairns [5] discovered that immersion is the degree to which a user is involved with a game. They suggested that the degree of involvement varies with time and is controlled by barriers which can be cleared through human activity such as concentration.

The three recognized reasons which can lead (independently or along with other reasons) to psychological immersion are the subjective sense of being surrounded or experiencing multisensory stimulation, absorption in the narrative or the depiction of the narrative, and absorption when facing strategic or tactical challenges. These are described in the following paragraphs.

\subsubsection{Subjective Sense of Being Surrounded or Experiencing Multisensory Stimulation}

One of the prevalent conceptualizations of immersion is the sense of being surrounded or experiencing multisensory stimulation. Biocca and Delaney [27] dubbed this perceptual immersion: the extent of submersion of the user's perceptual system in the environment. It is 
believed that perceptual immersion can be measured objectively by "counting the number of the user's senses that are provided with input and the degree to which inputs from the physical environment are shut out" [28]. McMahan [1] stated that perceptual immersion can be achieved by blocking the external world and constraining the user's perception to the presented stimulus.

The role of sensory information in immersive gaming experiences was recognized by Ermi and Mäyrä [29] for the development of a gameplay experience model (sensory, challenge-based, and imaginative immersion model or SCI model). The authors called it sensory immersion: an overpowering of the sensory information from the real environment through large screens and powerful sounds to focus the user entirely on the stimulus. In their study on presence, Witmer and Singer [24] made the distinction between immersion and involvement such that the former is the subjective experience of being enveloped in an interactive environment and the latter is a psychological state which results from directing attention to the stimulus.

It may appear that what many researchers call perceptual or sensory immersion is a completely different perspective on immersion compared to psychological immersion. Nevertheless, it is instead a facilitator for psychological immersion since overpowering sensory information or blocking the stimuli from the immediate environment does not guarantee psychological immersion but can prevent "an exogenous shift of attention" [26] away from the activity; and consequently, influence psychological immersion. This can explain why the current trend for creating immersive audiovisual experiences is largely based on this idea of eliciting immersion (e.g. virtual reality, interactive audiovisual experiences, spatial audio, etc.).

\subsubsection{Absorption in the Narrative or the Depiction of the Narrative}

A number of studies draw attention to the importance of the narrative for immersive experiences. Adam and Rollings [6] conceptualized immersion in a story as "the feeling of being inside a story, completely involved and accepting the world and events of the story as real." In the context of video games, Ermi and Mäyrä [29] acknowledged the importance of the story elements which can mentally absorb the player for experiencing immersion. The two authors called this imaginative immersion on the premise that the player has an opportunity to exercise their imagination based on the narrative of the game. It was argued by Arsenault [30] that imaginative immersion should be modified to fictional immersion since one does not need to exercise their imagination to be immersed in the story. The different views on narrative immersion were summed up by Thon [26]: "narrative immersion refers to the player's shift of attention to the unfolding of the story of the game and the characters therein as well as to the construction of a situation model representing not only the various characters and narrative events, but also the fictional game world as a whole."

Ryan [18] categorized narrative immersion into spatial, temporal, and emotional immersion. Spatial immersion is experienced when an individual has a strong sense of space and enjoys the act of exploration. Temporal immersion: focused attention to the unfolding story [26], results from an individual's curiosity to know what happens next. Finally, emotional immersion occurs due to an individual's emotional attachment with the characters or the story [18]. It is strongest when an individual can relate to the presented situation and is emotionally invested in the story or the characters.

\subsubsection{Absorption when Facing Strategic and/or Tactical Challenges}

The influence of challenges on the experience of immersiveness is a closely examined topic since a considerable amount of immersion research is focused on video games. Ermi and Mäyrä [29] explained immersion in response to challenges as mental absorption which is reached due to a balance between challenges and abilities. They asserted that challenges can be related to strategic planning or thinking as well as the motor skills. Adam and Rollings [6] classified immersion due to challenges as strategic immersion and tactical immersion. The former can be observed when a player is absorbed in strategizing, calculating, and making choices while tactical immersion refers to the immersion which is encountered when one is completely attentive to the task on hand due to a stream of demands for quick reactions (e.g. playing video games which require swift tactile movements).

Arsenault [30] stated that one does not have to be challenged in order to be immersed. He proposed to modify challenge-based immersion to systematic immersion: it occurs when a player accepts the game's system (rules, 
laws, etc.) while rejecting the laws of physics as observed in the real world. Arsenault's idea of systematic immersion is applicable to non-participatory activities ${ }^{1}$ such as watching fictional movies where one isn't necessarily challenged by the content and may accept the existence of magic, for example.

In contrast to the idea of immersion being an individual's psychological state, an alternative outlook on immersion is the conception of immersion being an objective property of the system/technology which facilitates an experience. This perspective is discussed below.

\subsection{Immersion as an Objective Property of a System/Technology}

Proponents of this view believe that immersion is a set of characteristics of a system which can be objectively determined and quantified. In 2003, Slater [22] expressed the following:

\footnotetext{
${ }^{1}$ In this paper, non-participatory activity refers to an activity in which the user input or feedback does not influence or alter the outcome of the activity such as in a traditional movie-screening.
}

Let's reserve the term "immersion" to stand simply for what the technology delivers from an objective point of view. The more the system delivers displays (in all sensory modalities) and tracking that preserves fidelity in relation to their equivalent real-world sensory modalities, the more that is "immersive."

Slater's description implies that increasing the number of channels and loudspeakers augments immersiveness, irrespective of the content, context, and individual preferences. Evidently, a shortcoming of this conceptualization is that it does not account for perceptual limits, content, context, and individual factors such as preference and mood. Slater rejects the notion that immersion is a subjective experience. It is important to mention that the conviction of immersion being an objective property of a system/technology is held by a small minority in the literature. The term system immersion [31] can be used to distinguish this view on immersion from the others.

The concepts reviewed in this section are summarized in Figure 1. A definition of immersion is proposed

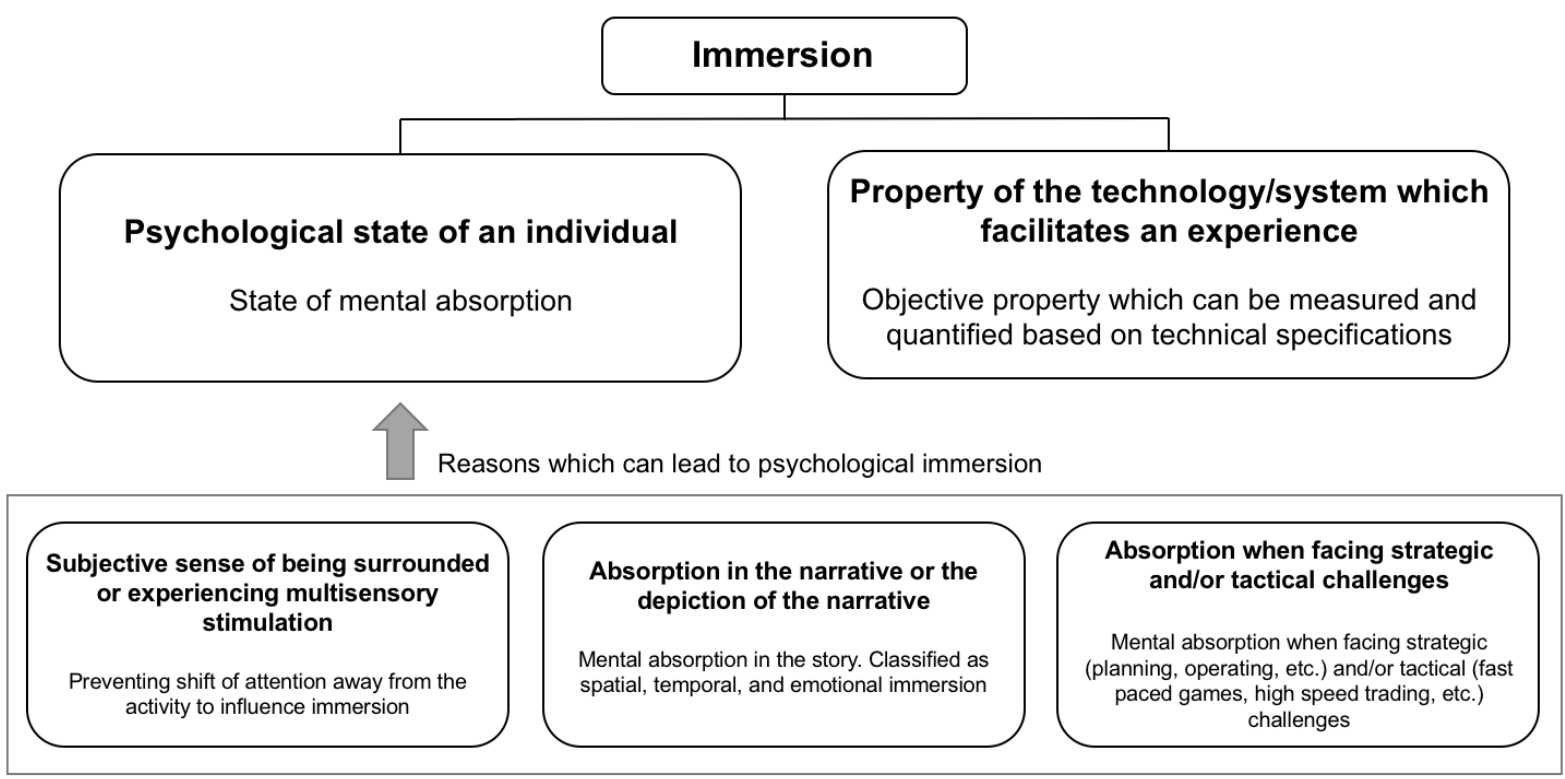

Fig. 1: Summary of the literature review presented in this paper. Although the subjective sense of being surrounded or experiencing multisensory stimulation, absorption in the narrative or the depiction of the narrative, and absorption when facing strategic and/or tactical challenges are seen as different perspectives on immersion, they are viewed as reasons which can lead to psychological immersion in this paper. Refer to Section 3 for the proposed definition of immersion from a psychological standpoint. 
in the next section based on the presented literature review.

\section{Proposed Definition}

The motivation for studying immersion is to recognize the influencing factors so that they may be varied to augment experiences. Hence, it is crucial to establish a definition of immersion on the basis of which the underlying phenomenon can be investigated. In this section, an adaptable definition of immersion is proposed and illustrated using immersive potential and immersive tendency.

The conceptualization of immersion being an objective property of the system may not always lead to a perceptual difference, rendering it insignificant for the goal of augmenting experiences. Additionally, Slater's conception of immersion [21,22] relies on the availability of an external system because it is highly focused on virtual reality applications, restricting the generalizability of the concept. The role of the individual is of paramount importance since experiences are, by their very nature, highly subjective. Hence, the notion of immersion being a property of a system/technology can be rejected. Taking into account the wide range of fields where immersion is applied, the following definition is proposed:

Immersion is a phenomenon experienced by an individual when they are in a state of deep mental involvement in which their cognitive processes (with or without sensory stimulation) cause a shift in their attentional state such that one may experience disassociation from the awareness of the physical world.

Based on this definition, immersion is a mental state which is why sensory stimulation is not required to experience immersion (for example, daydreaming can be an immersive experience). It is important to consider all sensory modalities for determining immersion since the presented stimuli may stimulate only a few senses but humans continue to receive input from all the senses which can influence immersion. Therefore, all the factors which can either facilitate or disrupt immersion must be considered. It is unreasonable to merely examine the stimulus or the system to determine immersion. While the system and the content can certainly affect immersion, they are not immersive independent of the subject. The idea of immersive potential can add clarity to the above explanation:

Immersive potential: The potential of a system or content to elicit immersion.

For a given piece of content presented by a system which does not change, the immersive potential remains constant. It is important to note that the immersive potential does not simply increase with the technical specification of the system. Instead, it depends on its ability to elicit immersion. The immersive potential is barred by the human perceptual limits and the changes to a system must lead to a discernible perceptual change to alter its immersive potential.

In addition to the system and the content, immersion also depends on the state of the individual at the moment in time, as well as their immersive tendency, which is defined as follows:

Immersive tendency [24]: An individual's predisposition to experience immersion.

It can be assumed that the immersive tendency of an individual remains constant during the course of an experiment which is conducted over a short duration of time $^{2}$. The immersive tendency can be determined with the help of questionnaires $[24,32]$ to learn if certain individuals can get immersed relatively easily compared to others.

The four factors which can influence immersion are: 1) the system (physical properties of the reproduction system and the content), 2) narrative (content), 3) environment (physical environment and the contextual conditions), and 4) individual factors (affective states, mood, preference, skills, previous knowledge, expertise, goals, motivation, etc.). These are similar to those which affect the quality of experience (QoE) [33] since immersion is an experience which is dependent on an individual's cognitive state and preference for the content. Nonetheless, the concepts of QoE and immersive experiences should not be confused. An experience must elicit immersion to qualify as an immersive experience while the QoE, theoretically, can be assessed for any experience.

\footnotetext{
${ }^{2}$ Immersive tendency can change over time due to training, learning, experience, changes in personality, etc. Since these factors do not normally vary within a short duration of time (e.g. over the course of a few days), these can be assumed to be constant for conducting experiments.
} 


\section{Other Cognitive Concepts}

As noted previously, immersion is often used interchangeably with presence, flow, and transportation. In this section, these different concepts are weighed and distinguished from immersion on the basis of the proposed definition.

\subsection{Presence}

The term presence has been a crucial research topic in video game and virtual reality studies since the 90 s and has been used to describe experiential phenomena in a range of diverse realms such as communication, engineering, psychology, and philosophy [19]. Similar to immersion, there are contradicting opinions regarding the definition of the term and the suitable methods to measure and quantify presence remain debatable.

Presence has been defined as "the psychological sense of being in a virtual environment;" [23] "[the] extent to which a person's cognitive and perceptual systems are tricked into believing they are somewhere other than their physical location;" [34] and the feeling of being in the game [5, 35, 36, 37, 38, 39]. This is evidence that the term presence refers to the sense of being present in an environment which is not purely the physical environment around us.

Jennett et al. [7] stated that a double disassociation exists between immersion and presence. For instance, one can be immersed when listening to electronic music but may not feel present due to a lack of spatial cues in the content, limited spatial fidelity of the reproduction system, etc. On the other hand, playback over headphones of a binaural recording of restaurant ambience can make one feel as if they are present at the restaurant but such a scenario would most likely fail to immerse the listener due to the rendering system and the content's low immersive potential. This double disassociation can also be observed in participatory activities such as the one that Jennett et al. [7] illustrated through the example of playing Tetris (an abstract game) on a 2D screen. It is unlikely that the player will feel present in an environment where there are blocks falling around them; however, the player can still be immersed in the activity. Even so, when asked to perform a boring task in a virtual simulation, one can feel present in the environment but not be mentally involved; and thus, immersion will be absent. It is worth noting that immersion and presence can be experienced simultaneously such as when listening to a highly spacious recording of one's favorite classical music piece or playing an engaging game in virtual reality.

\subsection{Transportation}

Transportation is a term which is used when studying narrative worlds to describe the feeling which is commonly described as being lost in the story. It has been defined as "immersion or absorption into a narrative world" [40] and as a "state of detachment from the world of origin" [41]. Discussions of transportation are similar to those of immersion: the idea of being in a different world, through media (here, any form of narrative) and experiencing disassociation from the awareness of the world of origin. Although an attempt has been made to spot subtle differences between the concepts of immersion and transportation [41], there is an apparent lack of adequate and conclusive evidence. Consequently, transportation can be viewed as immersion which is fundamentally focused on the narrative.

\subsection{Flow}

The concept of flow was pioneered by Csikszentmihalyi who defined flow as "the state in which people are so involved in an activity that nothing else seems to matter; the experience itself is so enjoyable that people will do it even at great cost, for the sheer sake of doing it" [42]. He identified the balance between ability and challenge, concentration/attention, clear goals, immediate feedback, escape from everyday life, sense of personal control (lack of a sense of worry), loss of selfconsciousness, and altered sense of time as the eight components of flow [42]. Nevertheless, the minimum requirements which qualify an experience as a flow experience have not been established [43]. The descriptions, causes, and symptoms of a flow experience are inconsistent in the literature and should be approached with caution. In addition, some of the components such as the balance between ability and perceived challenge are open to interpretation, causing trouble in the qualification of experiences.

The distinction between flow and immersion was challenged by Michailidis et al. [39] who suggested that there is a lack of evidence to conclude that the two concepts are dissimilar. However, even though there is an overlap between the two concepts, they should 
not be considered synonymous since flow is an "all-ornothing" experience [44] while immersion may be a graded experience [5]. Flow is an extreme experience $[4,7,45]$ which limits it to optimal, positive experiences. Additionally, the absence of key components of flow (e.g. balance between ability and challenge, clear goals, and immediate feedback) in activities such as watching a movie or listening to music essentially disqualifies passive activities as flow experiences. Naturally, a piece of music or a movie can certainly engage the user and induce immersion; exemplifying that flow and immersion are independent ideas.

\section{Distinction Between Envelopment and Immersion}

Envelopment is a widely studied topic in concert hall acoustics. Nonetheless, with the growing popularity of spatial audio, envelopment is being used in a much broader sense. Rumsey [46] classified envelopment as environmental envelopment and source-related envelopment. Environmental envelopment, also known as listener envelopment (LEV), is the feeling of being surrounded by the reverberant sound field while sourcerelated envelopment can be defined as "envelopment by one or more dry or direct foreground sound sources" [46]. LEV is primarily dependent on late arriving reflections [47] while source-related envelopment can be experienced when sounds are placed around the listener [48].

Francombe et al. [3] found that 90 percent of the participants felt that envelopment and immersion were synonymous in an experiment conducted for determining the attributes of different spatial audio reproduction methods. This can be explained by the use of the analogy: 'experience of swimming underwater,' for describing both, immersion and envelopment. Although the differences between these terms are often considered to be subtle, there is a noteworthy distinction: envelopment is perceptual whereas immersion is cognitive. Furthermore, a double disassociation exists between immersion and envelopment. For instance, monophonic reproduction of one's preferred music can deliver an immersive experience but would not be reported as being enveloping. In contrast, reproduction over headphones of a binaural recording of restaurant ambience can be perceived to be enveloping but will likely fail to immerse the listener due to a lack of engaging narrative and low immersive potential. Hence, one can be immersed when envelopment is absent and vice versa. It is important to note that even though immersion and envelopment are distinct ideas, they may be correlated.

Following the proposed definition and outlining the differences between the interchangeably used terms and immersion, the succeeding section presents an overview of experimental paradigms for measuring immersion. These methods include subjective (questionnaires) and physical and behavioral measurement methods.

\section{Measuring Immersion}

The challenge with measuring immersion is twofold: the absence of a definitional consensus and a lack of knowledge regarding the causes and the attributes of immersion. The fragile nature of immersion [20] also adds to the complexity of measuring immersion.

The following sub-sections provide an overview of experimental paradigms and discuss their advantages and limitations for measuring immersion. Please note that the definition of the terms immersion and presence may differ from those determined earlier in Sections 3 and 4.1 due to a lack of definitional consensus.

\subsection{Questionnaires}

Questionnaires developed for measuring presence [24, $25,49,50,51]$, engagement $[35,52]$, and transportation [40] with immersion as a factor under investigation can be adapted for measuring immersion. The multidimensionality of the concept, nonetheless, varies the particular dimension (narrative, system, etc.) examined by these questionnaires (see $[25,53,54]$ ). In addition, many of the questionnaires are context-specific (video games, virtual reality, audiovisual, books, etc.) and cannot be adapted directly. For instance, questionnaires based on transportation or narrative engagement principally focus on the narrative of the content while those for video games $[7,35,53,55]$ are aimed at interactive experiences. To navigate this issue, Lessiter et al. [51] developed the Independent Television Commission Sense of Presence Inventory (ITC-SOPI) which is independent of the media system and the content properties; similar in concept to the Measurement, Effects, Conditions Spatial Presence Questionnaire (MEC-SPQ) proposed by Vorderer et al. [50]. 
Post-experience questionnaires are attractive as they do not interfere with the experience and are easy for the subjects to use. Notwithstanding, such measurements can lead to inaccurate recall and recency effect [56]. The measurement of temporal variation of immersion is also barred by the post-experience nature of the method. Ijsselsteijn et al. [57] attempted to measure the variation of presence over time using a slider which can potentially disrupt the sense of presence by including elements from the real environment in the virtual experience; and hence, lead to inaccurate measurements.

\subsection{Physiological and Behavioral Measures}

Physiological and behavioral measures provide an objective and non-invasive way to measure immersion. Results from such measurements must be interpreted prudently as the relationship between the concepts (immersion, presence, etc.) and their suspected attributes (spatial and temporal disassociation, altered emotional state, etc.) are not well-established.

A number of studies have suspected a lack of awareness of the non-mediated world to be one of the fundamental attributes of immersion [26, 40, 58] which can be investigated through various behavioral and physiological methods. On the behavioral level, secondary task reaction time (STRT) $[59,60,61]$ can be used to measure attention to the non-mediated world. The assumption for immersion research is that if the cognitive resources are primarily allocated to the mediated experience, less attention would be available for other tasks; thus, the reaction time for the secondary tasks will be longer. However, Klimmt et al. [59] reported a weak negative correlation between attentional measures and the STRT responses which contradicts the assumption stated above.

On the physiological level, Haffegee and Barrow [62] and Cox et al. [63] have recommended eye tracking to investigate the attentional attributes. Jennett et al. [7] found different fixation patterns between immersive and non-immersive conditions which was supported by Wissmath et al. [64]. Nevertheless, the results of eye-tracking measures on immersion are sparse and further research is required to understand the underlying relationship.

A lack of awareness of the non-mediated world can also be viewed as an alteration of time perception $[5,7,65]$; however, the links between immersive experiences and time perception are unclear [5].

Brain responses have been proposed to measure immersion in a non-invasive manner. Electroencephalography (EEG test) has been conducted to measure event-related potential [66] and brain oscillations [67] as a measure of immersion. Attempts have also been made to measure presence with functional magnetic resonance imaging (fMRI) [68, 69, 70] and EEG [71, 72]. Michailidis et al. [39] found that flow and immersion may share some neural mechanisms different from the ones associated with presence based on their review of flow, immersion, and presence.

It is believed that immersion can also be investigated via emotions [7, 40, 52, 53], but the results obtained through studies based on electro-dermal activity (EDA) $[73,74,75]$ do not provide evident conclusions.

Thus, a number of physiological and behavioral measures can be explored to measure immersion physically and in non-invasive ways. Nevertheless, these methods should be used carefully due to the lack of evidence confirming the links between the concepts to be assessed and the measured attribute(s).

\section{Implications and Future Work}

The literature review illustrates that there is a difference of opinion among researchers which must be resolved to develop a common understanding of the term across disciplines. Even though absorption in the narrative, absorption when facing intellectual and/or tactical challenges, and the sense of being enveloped have been viewed as reasons which lead to psychological immersion in this paper, additional research is required to analyze if the phenomena they cause warrant the classification of psychological immersion.

Studying the immersive potential of a system is of great interest to researchers and engineers. Aspöck et al. [76] approached immersion as the sense of being surrounded/enveloped to investigate the immersion of spatial audio reproduction systems. They used the questionnaire developed by Colsman et al. [77] which assumes attribution (causality), attention, room perception, and source perception to be the four key aspects which influence immersion. These factors are different from the factors identified in Section 3 due to a difference in the definition of immersion. An apparent shortcoming of such an approach is that there is a risk of measuring the 
presumed aspects rather than immersion, due to a lack of information regarding the links between them. The measured phenomenon may be different from immersion since the experience is not assessed to verify its qualification as an immersive experience.

Eaton and Lee [78] surveyed audio professionals to identify the quantifying factors for auditory immersion in VR from a set of perceptual auditory factors (envelopment, clarity, localization, etc.) and technical features (latency, headphone equalization, etc.). They concluded that all of the listed factors in the survey are important for auditory immersion. The prevailing issue with such a study is that it perpetuates the general understanding of the term rather than assessing the underlying framework. We assert that although the system can influence immersion, it is not the determining factor for immersion.

In addition to the system, the content plays an important role in the experience of immersion. It should not be assumed that a particular stimulus will immerse all the subjects under consideration. Furthermore, there is no guarantee that a subject will experience immersion in every trial for a given stimulus since every trial modifies the subject's knowledge and expectations of the stimulus. Such modifications could potentially lead to bias, influencing the likelihood of a subject experiencing immersion when a stimulus is repeated. Given the lack of understanding regarding the experience of immersion when a stimulus is repeated, it is important that the subjects evaluate a stimulus only once in an experiment until further research is conducted. Subjects' familiarity with the content should also be documented and accounted for in the analysis. Hence, to achieve the desired statistical power, it is important to have a sufficient number of subjects and stimuli for assessment since repetitions cannot be performed.

Considering the limited knowledge regarding the temporal nature of immersion and the time required for a subject to experience immersion, it is suspected that the subjects would require several minutes to reach the state of immersion [79]. In addition, the audiovisual excerpts used as stimuli must be standalone pieces which do not require prior knowledge about the presented narrative.

Immersion is largely dependent on the immersive tendency, the state of an individual at the time of an experience, and the significance of the content to the subject.
While immersive tendency can be gauged by questionnaires, the fluctuating factors such as mood, preference, and affective states are rather difficult to assess. The significance of the content to an individual is largely unquantifiable, adding to the complexity of assessing an immersive experience.

The major challenge for quantifying immersion is the development of suitable measurement methods. Since not all experiences are immersive, future work should aim to first separate immersive experiences from nonimmersive experiences. This step is critical to ensure that immersion was elicited during the assessed experience in order to avoid erroneous measurements. The determination of immersive experiences can be followed by discerning whether immersion is a bipolar or a graded experience. Although it has been suggested that immersion is a graded experience for participatory activities [5], there is insufficient evidence to conclude the same for non-participatory activities. The nature of immersion will dictate if the experiences can be evaluated on a nominal or interval scale.

Subsequently, immersion could be assessed for a variety of audiovisual experiences including virtual reality. Future work should investigate the influence of physical parameters of the system (e.g. number of channels in the audio rendering system) on the immersive audiovisual experience. Understanding the influence of the factors affecting immersion can be helpful in accomplishing the goal of augmenting experiences for the users.

\section{Summary}

In this paper, a non-exhaustive review of literature on immersion has been presented, on the basis of which the descriptions of immersion have been categorized into two paradigms: an individual's psychological state and the objective property of the technology or the system which facilitates an experience. The authors of this paper emphasize that immersion is a cognitive construct on the basis of which an adaptable definition of immersion from a psychological perspective has been proposed in Section 3.

The terms immersive potential and immersive tendency are suggested to develop the foundation for conducting experiments and quantifying immersion. Based on the proposed definition, immersion is contrasted with 
presence, transportation, flow, and envelopment to signify the underlying differences between the ideas. The system, content, environment, and individual factors are identified as the four factors which can influence immersion.

The overview of the subjective and objective measurement techniques illustrates the scarcity of reliable and robust methods for measuring immersion, suggesting a clear need for additional research. To study immersive experiences, it is important to understand each of the four factors which can influence immersion (the system, narrative, environment, individual factors) and their complex interaction. Approaching immersion as one complete experience rather than merely investigating the system or the stimuli is of paramount importance. Identification of the attributes and causes of immersion will facilitate the study of immersion, and eventually, create new avenues for augmenting experiences.

\section{Acknowledgement}

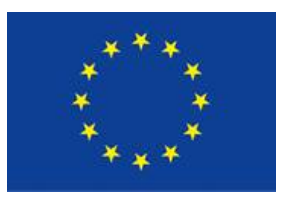

This project has received funding from the European Union's Horizon 2020 research and innovation programme under the Marie Skłodowska-Curie grant agreement No.765911. The authors would like to thank the Bang \& Olufsen research group for their valuable time and input.

\section{References}

[1] McMahan, A., "Immersion, Engagement, and Presence: A Method for Analyzing 3-D Video Games," in The Video Game Theory Reader, pp. 67-86, Routledge, London, 2003.

[2] Berg, J., “The Contrasting and Conflicting Definitions of Envelopment," in Audio Engineering Society Convention 126, 2009.

[3] Francombe, J., Brookes, T., and Mason, R., "Evaluation of Spatial Audio Reproduction Methods (Part 1): Elicitation of Perceptual Differences," Journal of Audio Engineering Society, 65(3), pp. 198-211, 2017.

[4] Sanders, T. and Cairns, P., "Time Perception, Immersion and Music in Videogames," in Proceedings of the 24th BCS Interaction Specialist Group Conference, BCS '10, 2010.
[5] Brown, E. and Cairns, P., "A Grounded Investigation of Game Immersion," in CHI '04 Extended Abstracts on Human Factors in Computing Systems, CHI EA ’04, 2004.

[6] Adams, E. and Rollings, A., Fundamentals of Game Design, Prentice-Hall, Inc., Upper Saddle River, NJ, USA, 2006.

[7] Jennett, C., Cox, A. L., Cairns, P., Dhoparee, S., Epps, A., Tijs, T., and Walton, A., "Measuring and Defining the Experience of Immersion in Games," International Journal of HumanComputer Studies, 66(9), pp. 641-661, 2008.

[8] Reichenbach, D. J., "Losing Time and Space: Experiencing Immersion," in Space, Time and the Limits of Human Understanding, pp. 503-512, Springer International Publishing, Cham, Switzerland, 2017.

[9] Hudson, S., Matson-Barkat, S., Pallamin, N., and Jegou, G., "With or Without You? Interaction and Immersion in a Virtual Reality Experience," Journal of Business Research, 2018.

[10] Pausch, R., Proffitt, D., and Williams, G., "Quantifying Immersion in Virtual Reality," in Proceedings of the 24th Annual Conference on Computer Graphics and Interactive Techniques, SIGGRAPH '97, pp. 13-18, 1997.

[11] Morie, J. F., "Virtual Reality, Immersion, and the Unforgettable Experience," in Proceedings of SPIE, volume 6055, p. 60551X, 2006.

[12] Reaney, M., "Virtual Reality and the Theatre: Immersion in Virtual Worlds," Digital Creativity, 10(3), pp. 183-188, 1999.

[13] Dura, M. T., "The Phenomenology of the Musiclistening Experience," Arts Education Policy Review, 107(3), pp. 25-32, 2006.

[14] Amatriain, X., Hollerer, T., Kuchera-Morin, J., and Pope, S., "Immersive Audio and Music in the Allosphere," in International Computer Music Conference, 2007.

[15] Rooney, B., Benson, C., and Hennessy, E., "The Apparent Reality of Movies and Emotional Arousal: A study using Physiological and SelfReport Measures," Poetics, 40(5), pp. 405-422, 2012. 
[16] Visch, V. T., "The Emotional and Cognitive Effect of Immersion in Film Viewing," Cognition and Emotion, 24(8), pp. 1439-1445, 2010.

[17] Recuber, T., "Immersion Cinema: The Rationalization and Reenchantment of Cinematic Space," Space and Culture, 10(3), pp. 315-330, 2007.

[18] Ryan, M. L., Narrative as Virtual Reality: Immersion and Interactivity in Literature and Electronic Media, The Johns Hopkins University Press, Baltimore, MD, USA, 2003.

[19] Nilsson, N. C., Nordahl, R., and Serafin, S., "Immersion Revisited: A Review of Existing Definitions of Immersion and Their Relation to Different Theories of Presence," Human Technology, 12(2), pp. 108-134, 2016, exported from https://app.dimensions.ai on 2019/01/28.

[20] Murray, J. H., Hamlet on the holodeck: The future of narrative in cyberspace, MIT press, 2017.

[21] Slater, M. and Wilbur, S., “A Framework for Immersive Virtual Environments (FIVE): Speculations on the Role of Presence in Virtual Environments," Presence: Teleoperators \& Virtual Environments, 6(6), pp. 603-616, 1997.

[22] Slater, M., "A note on presence terminology," in Presence connect, 2003.

[23] Slater, M., Usoh, M., and Steed, A., "Depth of Presence in Virtual Environments," Presence: Teleoperators \& Virtual Environments, 3(2), pp. 130-144, 1994.

[24] Witmer, B. G. and Singer, M. J., "Measuring Presence in Virtual Environments: A Presence Questionnaire." Presence: Teleoperators \& Virtual Environments, 7(3), pp. 225 - 240, 1998.

[25] Lombard, M., Ditton, T. B., and Weinstein, L., "Measuring Presence: The Temple Presence Inventory," in Proceedings of the 12th Annual International Workshop on Presence, pp. 1-15, 2009.

[26] Thon, J.-N., "Immersion Revisited: On the Value of a Contested Concept," in Extending Experiences. Structure, Analysis and Design of Computer Game Player Experience, Lapland University Press, Rovaniemi, Finland, 2008.
[27] Biocca, F. and Delaney, B., "Immersive Virtual Reality Technology," in Communication in the Age of Virtual Reality, Lawrence Erlbaum Associates Inc, 1995.

[28] Lombard, M. and Ditton, T., "At the Heart of It All: The Concept of Presence," Journal of Computer-Mediated Communication, 3(2), 1997.

[29] Ermi, L. and Mäyrä, F., "Fundamental Components of the Gameplay Experience: Analysing Immersion," Worlds in play: International perspectives on digital games research, 37(2), pp. 37-53, 2005.

[30] Arsenault, D., "Dark Waters: Spotlight on Immersion," in EUROSIS Game-On North America 2005 Conference, Ghent, Belgium, 2005.

[31] Slater, M., "Measuring Presence: A Response to the Witmer and Singer Presence Questionnaire," Presence, 8(5), pp. 560-565, 1999.

[32] Weibel, D., Wissmath, B., and Mast, F. W., "Immersion in Mediated Environments: The Role of Personality Traits," Cyberpsychology, Behavior, and Social Networking, 13(3), pp. 251-256, 2010.

[33] Reiter, U., Brunnström, K., De Moor, K., Larabi, M.-C., Pereira, M., Pinheiro, A., You, J., and Zgank, A., "Factors Influencing Quality of Experience," in Quality of Experience: Advanced Concepts, Applications and Methods, pp. 55-72, Springer International Publishing, Cham, Switzerland, 2014.

[34] Patrick, E., Cosgrove, D., Slavkovic, A., Rode, J. A., Verratti, T., and Chiselko, G., "Using a Large Projection Screen As an Alternative to Head-mounted Displays for Virtual Environments," in Proceedings of the SIGCHI Conference on Human Factors in Computing Systems, CHI '00, pp. 478-485, 2000.

[35] Brockmyer, J. H., Fox, C. M., Curtiss, K. A., McBroom, E., Burkhart, K. M., and Pidruzny, J. N., "The Development of the Game Engagement Questionnaire: A Measure of Engagement in Video Game-Playing," Journal of Experimental Social Psychology, 45(4), pp. 624 - 634, 2009.

[36] Tamborini, R. and Skalski, P., "The Role of Presence in the Experience of Electronic Games," in 
Playing video games: Motives, responses, and consequences, pp. 225-240, Lawrence Erlbaum Associates Publishers, Mahwah, NJ, US, 2006.

[37] Zahorik, P. and Jenison, R. L., "Presence as Beingin-the-World," Presence: Teleoperators \& Virtual Environments, 7(1), pp. 78-89, 1998.

[38] Ryan, R. M., Rigby, C. S., and Przybylski, A., "The Motivational Pull of Video Games: A SelfDetermination Theory Approach," Motivation and Emotion, 30(4), pp. 344-360, 2006.

[39] Michailidis, L., Balaguer-Ballester, E., and He, X., "Flow and Immersion in Video Games: The Aftermath of a Conceptual Challenge," Frontiers in Psychology, 9, p. 1682, 2018.

[40] Green, M. C. and Brock, T. C., "The Role of Transportation in the Persuasiveness of Public Narratives." Journal of Personality and Social Psychology, 79(5), pp. 701-721, 2000.

[41] Van Laer, T., De Ruyter, K., Visconti, L. M., and Wetzels, M., "The Extended TransportationImagery Model: A Meta-Analysis of the Antecedents and Consequences of Consumers' Narrative Transportation," Journal of Consumer Research, 40(5), pp. 797-817, 2013.

[42] Csikszentmihalyi, M., Flow: The Psychology of Optimal Experience, Harper and Row, New York, 1990.

[43] Swann, C., Keegan, R. J., Piggott, D., and Crust, L., "A Systematic Review of the Experience, Occurrence, and Controllability of Flow States in Elite Sport," Psychology of Sport and Exercise, 13(6), pp. $807-819,2012$.

[44] Cairns, P., Cox, A., and Nordin, I., "Immersion in Digital Games: Review of Gaming Experience Research," in Handbook of Digital Games, IEEE, 2014.

[45] Frochot, I., Elliot, S., and Kreziak, D., "Digging Deep into the Experience - Flow and Immersion Patterns in a Mountain Holiday," International Journal of Culture, Tourism and Hospitality Research, 11(1), pp. 81-91, 2017.

[46] Rumsey, F., "Spatial Quality Evaluation for Reproduced Sound: Terminology, Meaning, and a
Scene-Based Paradigm," Journal of Audio Engineering Society, 50(9), pp. 651-666, 2002.

[47] Bradley, J. S. and Soulodre, G. A., "Objective Measures of Listener Envelopment," The Journal of the Acoustical Society of America, 98(5), pp. 2590-2597, 1995.

[48] George, S., , Zielinski, S., Rumsey, F., and Bech, S., "Evaluating the Sensation of Envelopment Arising from 5-Channel Surround Sound Recordings," in Audio Engineering Society Convention 124, 2008.

[49] Schubert, T., Friedmann, F., and Regenbrecht, H., "The Experience of Presence: Factor Analytic Insights," Presence: Teleoperators \& Virtual Environments, 10(3), pp. 266-281, 2001.

[50] Vorderer, P., Wirth, W., Gouveia, F. R., Biocca, F., Saari, T., Jäncke, F., Böcking, S., Schramm, H., Gysbers, A., Hartmann, T., et al., "MEC Spatial Presence Questionnaire (MEC-SPQ): Short Documentation and Instructions for Application," Report to the European community, project presence: MEC (IST-2001-37661), 3, 2004.

[51] Lessiter, J., Freeman, J., Keogh, E., and Davidoff, J., "A Cross-Media Presence Questionnaire: The ITC-Sense of Presence Inventory," Presence: Teleoperators \& Virtual Environments, 10(3), pp. 282-297, 2001.

[52] de Graaf, A., Hoeken, H., Sanders, J., and Beentjes, H., "The Role of Dimensions of Narrative Engagement in Narrative Persuasion," Communications, 34(4), pp. 385-405, 2009.

[53] Qin, H., Patrick Rau, P.-L., and Salvendy, G., "Measuring Player Immersion in the Computer Game Narrative," International Journal of Human-Computer Interaction, 25(2), pp. 107133, 2009.

[54] Nordin, A. I., Denisova, A., and Cairns, P., "Too Many Questionnaires: Measuring Player Experience Whilst Playing Digital Games," in Seventh York Doctoral Symposium on Computer Science \& Electronics, volume 69, 2014.

[55] IJsselsteijn, W., De Kort, Y., and Poels, K., “The Game Experience Questionnaire,” 2013. 
[56] Insko, B. E., "Measuring Presence: Subjective, Behavioral and Physiological methods." in Studies in new technologies and practices in communication. Being there: Concepts, effects and measurements of user presence in synthetic environments, pp. 109-119, Ios Press, 2003.

[57] IJsselsteijn, W., de Ridder, H., Hamberg, R., Bouwhuis, D., and Freeman, J., "Perceived Depth and the Feeling of Presence in 3DTV," Displays, 18(4), pp. 207-214, 1998.

[58] Smith, S., Marsh, T., Duke, D., and Wright, P., "Drowning in Immersion," in Proceedings of UKVRSIG, volume 98, pp. 1-9, Citeseer, 1998.

[59] Klimmt, C., Hartmann, T., Gysbers, A., and Vorderer, P., "The Value of Reaction-Time Measures in Presence Research: Empirical Findings and Future perspectives," in Proceedings of the 8th International Workshop on Presence, 2005.

[60] Bracken, C. C., Pettey, G., and Wu, M., "Revisiting the Use of Secondary Task Reaction Time Measures in Telepresence Research: Exploring the Role of Immersion and Attention," AI \& Society, 29(4), pp. 533-538, 2014.

[61] Basil, M., "Secondary Task Reaction Time," in The International Encyclopedia of Communication Research Methods, pp. 1-9, 2017.

[62] Haffegee, A. and Barrow, R., "Eye tracking and gaze-based interaction within immersive virtual environments," in International Conference on Computational Science, pp. 729-736, 2009.

[63] Cox, A. L., Cairns, P., Berthouze, N., and Jennett, C., "The use of eyetracking for measuring immersion," in CogSci 2006 Workshop: What have eye movements told us so far, and what is next, 2006.

[64] Wissmath, B., Stricker, D., Weibel, D., Siegenthaler, E., and Mast, F. W., "The illusion of being located in dynamic virtual environments. Can eye movement parameters predict spatial presence?' Journal of Eye Movement Research, 3(5), 2010.

[65] Brooks, K., "There is nothing virtual about immersion: Narrative immersion for VR and other interfaces," 2003.
[66] Allison, B. Z. and Polich, J., "Workload assessment of computer gaming using a single-stimulus event-related potential paradigm," Biological psychology, 77(3), pp. 277-283, 2008.

[67] Kruger, J.-L., Doherty, S., and Ibrahim, R., "Electroencephalographic beta coherence as an objective measure of psychological immersion in film," Rivista internazionale di tecnica della traduzione, 2017.

[68] Baumgartner, T., Speck, D., Wettstein, D., Masnari, O., Beeli, G., and Jäncke, L., "Feeling present in arousing virtual reality worlds: prefrontal brain regions differentially orchestrate presence experience in adults and children," Frontiers in Human Neuroscience, 2, p. 8, 2008.

[69] Jäncke, L., Cheetham, M., and Baumgartner, T., "Virtual reality and the role of the prefrontal cortex in adults and children." Frontiers in Neuroscience, 3, p. 6, 2009.

[70] Bouchard, S., Dumoulin, S., Talbot, J., Ledoux, A.-A., Phillips, J., Monthuy-Blanc, J., LabontéChartrand, G., Robillard, G., Cantamesse, M., and Renaud, P., "Manipulating subjective realism and its impact on presence: Preliminary results on feasibility and neuroanatomical correlates," Interacting with Computers, 24(4), pp. 227-236, 2012.

[71] Wiederhold, B. and Riva, G., "Measuring presence during the navigation in a virtual environment using EEG," Annual Review of Cybertherapy and Telemedicine 2013: Positive Technology and Health Engagement for Healthy Living and Active Ageing, 191, p. 136, 2013.

[72] Kober, S. E., Kurzmann, J., and Neuper, C., "Cortical correlate of spatial presence in $2 \mathrm{D}$ and $3 \mathrm{D}$ interactive virtual reality: an EEG study," International Journal of Psychophysiology, 83(3), pp. 365-374, 2012.

[73] Dillon, C., Keogh, E., Freeman, J., and Davidoff, J., "Aroused and immersed: the psychophysiology of presence," in Proceedings of 3rd International Workshop on Presence, Delft University of Technology, Delft, Netherlands, pp. 27-28, 2000.

[74] Dillon, C., Keogh, E., and Freeman, J., "It's been emotional': Affect, physiology, and presence," in Proceedings of Presence, pp. 223-232, 2002. 
[75] Baumgartner, T., Valko, L., Esslen, M., and Jäncke, L., "Neural correlate of spatial presence in an arousing and noninteractive virtual reality: an EEG and psychophysiology study," CyberPsychology \& Behavior, 9(1), pp. 30-45, 2006.

[76] Aspöck, L., Colsman, A., Kohnen, M., and Vorlaender, M., "Investigating the immersion of reproduction techniques for room auralizations," in Jahrestagung für Akustik, DAGA 2016, pp. 565$568,2016$.

[77] Colsman, A., Aspöck, L., Kohnen, M., and Vorlaender, M., "Development of a questionnaire to investigate immersion of virtual acoustic environments," in Jahrestagung für Akustik, DAGA 2016, pp. 581-584, 2016.

[78] Eaton, C. and Lee, H., "Quantifying Factors of Auditory Immersion in Virtual Reality," in $A u$ dio Engineering Society Conference: 2019 AES International Conference on Immersive and Interactive Audio, 2019.

[79] ITU-T, "Subjective evaluation methods for gaming quality," Recommendation P.809, International Telecommunication Union, Geneva, 2018. 